\title{
CO-OCCURRENCE OF AGENESIS OF THE MAXILLARY LATERAL INCISORS WITH OTHER DENTAL ANOMALIES - A SYSTEMATIC REVIEW OF THE LITERATURE
}

\author{
Monika Parchańska-Kowalik, Wojciech Stós, Bartłomiej W. Loster \\ Department of Orthodontics, Dental Institute, Faculty of Medicine, Jagiellonian University Medical College, Cracow, Poland
}

\begin{abstract}
INTRODUCTION: Hypodontia of the maxillary lateral incisors is a developmental disorder whose genetic basis has been documented scientifically. Coexistence of hypodontia and other dental anomalies may indicate the occurrence of mutations within a given gene, the expression of which may be manifested in various phenotypic combinations.

ОвJеCтIVEs: The aim of the study was to determine the frequency of co-occurrence of agenesis of the maxillary lateral incisors with other dental anomalies and skeletal disorders, based on a systematic review of the literature.

MATERIAL AND METhods: An online database was searched using PubMed and Science Direct by entering the following keywords: maxillary lateral incisor agenesis and dental anomalies.

Results: A total of 1168 results were obtained. Eighteen articles from 1971-2016 that met the inclusion criteria were qualified for the analysis. Hypodontia of the maxillary lateral incisors is very often accompanied by other dental or skeletal disorders. These are most often: agenesis of another permanent tooth, ectopic maxillary canine eruption, distoangulation of mandibular second premolars, reduction of the overall size of the teeth, the occurrence of a peg-shaped or microdontic maxillary lateral incisor, the rectangular shape of crowns of the maxillary central incisors, taurodontism. Skeletal class III is much more common than in the general population and the vertical relationship is also reduced. The most frequent was distal relation on the molars and canines.

Conclusions: Based on information obtained from medical databases and library resources, it can be concluded that hypodontia of the maxillary lateral incisors is a condition predisposing to the co-occurrence of other disorders: size, structure, position and quantity of remaining permanent teeth. When planning orthodontic treatment, attention should also be paid to the frequent prevalence of skeletal III in these patients and to the reduced vertical relationship.
\end{abstract}

KEY WORDS: maxillary lateral incisor agenesis, dental anomalies, systematic literature review.

J Stoma 2018; 71, 4: 432-438

DOI: https://doi.org/10.5114/jos.2018.84649

\section{INTRODUCTION}

Hypodontia is a disorder consisting in congenital absence of at least one deciduous or permanent tooth bud, while oligodontia is the absence of at least six tooth buds excluding third molars [1]. The conducted studies have shown that the most frequently missing tooth is the mandibular second premolar (41\%), then the lateral incisor in the maxilla (22.9\%), in third place is the maxillary second premolar (21.2\%) and fourth

\section{JOURNAL OF} STOMATOLOGY CZASOPISMO STOMATOLOGICZNE

AdDress For CORRESPONDENCE: Monika Parchańska-Kowalik, DDS, PhD, Department of Orthodontics, Dental Institute, Faculty of Medicine, Jagiellonian University Medical College, 4 Montelupich St., 31-155 Cracow, Poland, phone: +48 1242454 02, e-mail: mkowalik137@gmail.com 
is the mandibular central incisor (3.5\%) [2]. Hypodontia is one of the most common developmental disorders whose genetic background has been scientifically confirmed [3]. The results of a genetic study by Woolf [4] confirm his hypothesis that part of the genetic code in patients with agenesis of the maxillary lateral incisors consists of a dominant autosomal gene (or genes) that exhibits reduced penetration and variable expression. It is also likely that this feature may in some cases be recessive or have polygenic inheritance. Recent studies have found mutations in the genes AXIN2, PAX9 and MSX1 in families with hypodontia of permanent teeth $[5,6]$. Other etiological factors of hypodontia and oligodontia include dental alveolar injuries, environmental factors such as rubella virus infection, action of chemical agents, medicines (e.g. thalidomide, chemotherapy) and radiotherapy [6]. The research carried out by Kjær [7, 8] confirms the hypothesis that disturbances in the tissues during the development process within the so-called fields of innervation may lead to agenesis of permanent teeth and most often the last teeth in the group are affected. The occurrence of hypodontia in deciduous teeth very often, but not always, correlates with the agenesis of their permanent successors [9]. Hypodontia and oligodontia are malformations that may be associated with other systemic or dental disorders [10-14]. Coexistence of hypodontia and other dental disorders such as ectopic canine eruption, microdontia, taurodontism and others confirms the genetic basis of the disorder and may indicate the occurrence of mutations within a given gene, whose expression may be manifested in various phenotypic combinations $[13,15,16]$. The incidence of maxillary lateral incisor agenesis (MLIA) is variable, depending on the studied population, and ranges from 2 to $5 \%[2,16-18]$. The incidence of MLIA is not sex dependent, and bilateral $(68.9 \%)$ is more common than unilateral (31.1\%) [16].

\section{OBJECTIVES}

The aim of the study was to determine the frequency of coexistence of agenesis of the maxillary lateral incisors with other dental anomalies and skeletal disorders, based on a systematic review of the literature.

\section{MATERIAL AND METHODS}

In order to determine the frequency of coexistence of agenesis of the maxillary lateral incisors with other dental anomalies and skeletal disorders, a systematic review of the literature was performed. An online database was searched using PubMed and Science Direct, using the following keywords: maxillary lateral incisor agenesis and dental anomalies. The analysis included randomized clinical trials, cohort studies and case-control studies, published until 2018. Case reports, literature reviews, letters to the editor, articles in a language other than English and Polish and articles not directly related to the subject of the research were excluded.

\section{RESULTS}

A total of 1168 results were obtained, mainly in English. Literature taken from found articles was used to obtain additional research. Eighteen articles from 19712016, which met the inclusion criteria, were qualified for the further analysis, all in English. The analysis of results from separate studies is presented in Table 1.

\section{ANALYSIS OF THE OBTAINED RESULTS}

Citak et al. [16] found that hypodontia of the maxillary lateral incisors in $23.3 \%$ of cases was accompanied by agenesis of permanent teeth other than third molars. The study group consisted of 90 patients with confirmed hypodontia of the maxillary lateral incisors. In the Garib et al. [19] trial, among the 126 patients with hypodontia of the lateral incisors in the maxilla, $18.2 \%$ of the patients were diagnosed with hypodontia of other permanent teeth with the exclusion of third molars. This result was over three times higher than in the general population (results were compared by researchers with reference data obtained from other studies). The frequency of agenesis of other permanent teeth in patients with MLIA was: second maxillary premolars: $10.3 \%$ (general population: $1.5 \%$ ), mandibular second premolars: $7.9 \%$ (general population: 3\%), third molars: $35.5 \%$ (general population: $20.7 \%$ ). There was no increased frequency in the occurrence of supernumerary teeth; it was $0.8 \%$, a result lower than in the general population (1.5\%), but it was not statistically significant. Celikoglu et al. [20] observed higher frequency of coexistence of agenesis of other permanent teeth $(9.6 \%)$ in patients with MLIA in the Turkish population, where the co-occurrence of supernumerary teeth was only $1.1 \%$, and this was not statistically significant. In the studies of Pinho et al. [21] hypodontia of other permanent teeth occurred in $12.8 \%$ of patients, with the most frequent being lack of second premolars both in the maxilla and the mandible (8.5\%).

Citak et al. [16] noted a statistically significant increase in the incidence of a peg-shaped microdontic lateral incisor in patients with unilateral maxillary lateral incisor agenesis (15.6\%) compared with the reference study. Celikoglu et al. [20] also observed that the unilateral agenesis of the lateral incisor is accompanied by a reduction in size or the presence of a conical contralateral incisor in $20.2 \%$ of cases. Another study conducted on a Jordanian patient population showed that as many as $50 \%$ of patients with unilateral MLIA have a reduced-width or conical opposite lateral incisor [22]. Results obtained by Stamatiou and Symons [23] showed that the reduction or conical shape of the contralateral 
TABLE 1. Coexistence of agenesis of the maxillary lateral incisors with other dental anomalies based on a systematic review of the literature

\begin{tabular}{|c|c|c|c|c|}
\hline Position & First author, year & Country & $\begin{array}{l}\text { MLIA } \\
\text { group size }\end{array}$ & Associated anomalies \\
\hline 4 & Woolf, 1971 & USA & 103 & Peg-shaped maxillary lateral incisor - 23.3\% \\
\hline 16 & Citak, 2016 & Turkey & 90 & $\begin{array}{c}\text { Agenesis of other teeth }-23.3 \% \\
\text { Dens invaginatus }-1.1 \% \\
\text { Dens evaginatus }-2.2 \% \\
\text { Peg-shaped maxillary lateral incisor }-15.6 \% \\
\text { Taurodontism }-42.2 \% \\
\text { Pulp stone }-10.0 \% \\
\text { Dilaceration }-18.9 \% \\
\text { Impaction of maxillary canine }-5.6 \%\end{array}$ \\
\hline 18 & Baidas, 2005 & Saudi Arabia & 30 & $\begin{array}{c}\text { Small lateral incisor } \\
\text { Small central incisors } \\
\text { Bolton index - maxillary insufficiency }\end{array}$ \\
\hline 19 & Garib, 2010 & Brazil & 126 & $\begin{array}{c}\text { Tooth agenesis - } 18.2 \% \\
\text { Maxillary second premolar agenesis }-10.3 \% \\
\text { Mandibular second premolar agenesis }-7.9 \% \\
\text { Third molar agenesis }-35.5 \% \\
\text { Supernumerary teeth }-0.8 \% \\
\text { Small maxillary lateral incisor }-38.8 \% \\
\text { Palatally displaced canine }-5.2 \% \\
\text { Mandibular second premolar distoangulation }-3.9 \% \\
\text { Mandibular second molar mesioangulation }-0.0 \%\end{array}$ \\
\hline 20 & Celikoglu, 2012 & Turkey & 94 & $\begin{array}{c}\text { Ectopic eruption of maxillary canine }-21.3 \% \\
\text { Reduced or peg-shaped maxillary lateral incisor }-20.2 \% \\
\text { Hypodontia of other teeth }-9.6 \% \\
\text { Dilaceration }-6.3 \% \\
\text { Impaction of maxillary canine }-5.3 \% \\
\text { Maxillary lateral incisor - canine transposition }-1.1 \% \\
\text { Transmigration of maxillary canine }-1.1 \% \\
\text { Supernumerary tooth }-1.1 \% \\
\text { Skeletal class I- } 55.3 \% \\
\text { Skeletal class } I-16.0 \% \\
\text { Skeletal class III }-28.7 \%\end{array}$ \\
\hline 21 & Pinho, 2005 & Portugal & 219 & $\begin{array}{c}\text { Hypodontia of other teeth }-12.8 \% \\
\text { Hypodontia of second premolar }-8.5 \% \\
\text { Reduced or peg-shaped maxillary lateral incisor }-59.5 \%\end{array}$ \\
\hline 22 & Albashaireh, 2006 & Jordan & 20 & Reduced or peg-shaped maxillary lateral incisor $-50.0 \%$ \\
\hline 23 & Stamatiou, 1991 & Australia & 91 & Reduced or peg-shaped maxillary lateral incisor - 33.0\% \\
\hline 25 & Yaqoob, 2011 & United Kingdom & 52 & $\begin{array}{l}\text { Small anterior teeth width - mean discrepancy } 0.42 \mathrm{~mm} \text { per tooth } \\
\text { in upper and } 0.33 \mathrm{~mm} \text { per tooth in lower anterior segments }\end{array}$ \\
\hline 26 & Mirabella, 2012 & Italy & 81 & $\begin{array}{l}\text { Smaller teeth width (from } 0.11 \text { to } 0.49 \mathrm{~mm} \text { ) } \\
\text { Microdontic contralateral maxillary lateral incisor }-44.9 \%\end{array}$ \\
\hline 27 & Olivadoti, 2009 & Italy & 31 & $\begin{array}{l}\text { Maxillary central incisors smaller by about } 0.38 \mathrm{~mm} \text { at contact points, } \\
\text { change of shape of central incisors - more rectangular }\end{array}$ \\
\hline 28 & Wright, 2016 & USA & 40 & $\begin{array}{l}\text { Small overall teeth width, in males posterior teeth in females } \\
\text { anterior teeth more often } \\
\text { Microdontic contralateral maxillary lateral incisor about } 1.27 \mathrm{~mm} \\
\text { smaller than in control group }\end{array}$ \\
\hline 29 & Al-Nimri, 2011 & Jordan & 246 & $\begin{array}{l}\text { Palatally displaced canine - } 12.6 \% \\
\text { Class I malocclusion - } 42.3 \% \\
\text { Class III malocclusion - } 25.2 \% \\
\text { Class II Div } 2 \text { malocclusion - } 20.3 \% \\
\text { Class II Div } 1 \text { malocclusion - } 12.2 \%\end{array}$ \\
\hline 30 & Becker, 1981 & Israel & 88 & Palatally displaced canine - 5.5\% \\
\hline
\end{tabular}


TABLE 1. (Continued)

\begin{tabular}{|l|c|c|c|c|}
\hline Position & First author, year & Country & $\begin{array}{c}\text { MLIA } \\
\text { group size }\end{array}$ \\
\hline 31 & Pinho, 2011 & Portugal & 147 & $\begin{array}{r}\text { Associated anomalies } \\
\text { Deviation of the maxillary dental midline } \\
\text { Molar and canine class II relationship }\end{array}$ \\
\hline 33 & Woodworth, 1985 & USA & 43 & $\begin{array}{r}\text { Craniofacial deviations from normal: smaller maxillary length, } \\
\text { smaller mandibular length, smaller anterior cranial base, nasal bone, } \\
\text { smaller vertical dimensions (anterior and posterior), } \\
\text { smaller mandibular plane angle, 10 }\end{array}$ \\
\hline 34 & Pinho, 2011 & Portugal & 147 & $\begin{array}{r}\text { Shorten nasolabial angle } \\
\text { Reduced anterior facial height }\end{array}$ \\
\hline 35 & Bassiouny, 2016 & Saudi Arabia & 52 & $\begin{array}{r}\text { Significant tendency for skeletal class III } \\
\text { Maxillary hypoplasia/retrognathia }\end{array}$ \\
\hline
\end{tabular}

incisor occurs in $33 \%$ of patients with unilateral form of MLIA. Researchers highlight the genetic basis of this condition. Also, Pinho et al. [21] demonstrated a reduction in the dimensions of the lateral incisor of the opposite side in $59.5 \%$ of patients. The Woolf [4] study showed that in $23.3 \%$ of patients with unilateral MLIA there is a conical shaped contralateral lateral incisor. In the study of Garib et al. [19] with unilateral agenesis of the maxillary lateral incisor, the size of the crown of the incisor of the opposite side is decreased (38.8\%). This result was very high compared to the reference studies carried out in 1998 by Bacetti [24], which estimated the incidence of this defect in the general population at $4.7 \%$. Baidas and Hasim [18], when measuring the width of individual teeth and analysis of the Bolton anterior index, found that in patients with unilateral MLIA, the width of the lateral incisor of the opposite side is $1 \mathrm{~mm}$ lower than the standard $(5.5 \mathrm{~mm}$, with the standard of $6.5 \mathrm{~mm}$ accepted by researchers). Maxillary central incisors showed a reduction in width. Analysis of the Bolton anterior index showed the reduction of dental material, both in the case of bilateral and unilateral form of MLIA. Also, a study conducted by Yaqoob et al. [25] confirmed the reduction in the overall tooth size in patients with bilateral agenesis of the maxillary lateral incisors compared to the control group, which comprised fully dented patients. The difference was noticeable in both the upper and lower dental arch. Researchers compared the width of six front teeth. The mean values resulting from the measurements of the maxillary teeth width in MLIA patients revealed a reduction in the dimensions of each tooth by an average of $0.42 \mathrm{~mm}$, and in the case of mandibular teeth they were smaller by an average of $0.33 \mathrm{~mm}$. Similar results, however, considering the width of 12 teeth in both the maxilla and the mandible, were obtained by Mirabella et al. [26]. Their study showed that the width of permanent teeth in patients with both unilateral and bilateral hypodontia of the maxillary lateral incisors is on average 0.11 to $0.49 \mathrm{~mm}$ per tooth lower than in the control group with full permanent dentition. Only the maxillary first molars did not show a reduced size. There was no difference in crown width compared to the control group in patients with bilateral and unilateral hypodontia of the maxillary lateral incisors. Researchers also evaluated the prevalence of the microdontic opposite side lateral incisor in patients with unilateral MLIA. The frequency of the abovementioned anomaly was $44.8 \%$. Mirabella et al. [26] also underlined the fact of the MLIA genetic background. According to the researchers, the gene, causing hypodontia of the maxillary lateral incisors, reduces the total dimensions of the teeth. The authors emphasized how important from a clinical point of view the research they conducted is. The front teeth, due to the reduced size, will often require aesthetic restoration to ensure efficient occlusion and good aesthetics, both in the opening of space for the future prosthetic or implant prosthetic restoration as well as in the orthodontic closure of the spaces. Another important clinical study is the work of Olivadoti et al. [27]. They assessed the shape and width of maxillary central incisors at the contact points and in the $1 / 3$ gingival. The obtained results indicated a reduction in the dimensions of these teeth in patients with MLIA at the level of contact points by an average of $0.38 \mathrm{~mm}$, in the absence of a significant reduction in the width in $1 / 3$ gingival. This indicated a change in the shape of the central incisors to more rectangular ones. Researchers emphasize the need for aesthetic correction of the shape of these teeth in patients with MLIA. Wright et al. [28] measured the width of the teeth in 40 patients with unilateral and bilateral hypodontia of the lateral incisors. The results indicated a reduction in the dimensions of the teeth. In men with MLIA, the lateral teeth were $0.28 \mathrm{~mm}$ to $0.78 \mathrm{~mm}$ smaller than the control group, and women showed a reduction in the dimensions of the anterior teeth by $0.22 \mathrm{~mm}$ to $0.42 \mathrm{~mm}$. In cases of unilateral MLIA, the contralateral incisor showed an average width of $5.39 \mathrm{~mm}$, compared with the average width of the maxillary lateral incisors in the control group of $6.66 \mathrm{~mm}$, which gave a difference of $1.27 \mathrm{~mm}$. Co-occurrence of the conical tooth was also more frequently observed. 
Garib et al. [19] found an increased frequency of palatally displaced canines (PDC) in patients with hypodontia of the lateral incisors in maxilla at $5.2 \%$, which was statistically significant. Citak et al. [16] did not report a higher incidence of impacted canines in patients with MLIA (5.6\%). The results obtained in both studies are similar to each other, and the difference in their interpretation may be caused by differences in the values in the reference data and the size of the studied groups. In the Garib et al. [19] trial, the incorrect positioning of other permanent teeth was also assessed: distoangulation of second premolars in the mandible $(3.9 \%$ in patients with MLIA, and only $0.2 \%$ in the reference study of the general population) and mesial inclination of the second molar in the mandible (no statistically significant differences). Al-Nimri and Bsoul [29] found a positive correlation between the occurrence of palatally impacted canines and the agenesis of the lateral incisors in the maxilla. The study group consisted of 246 patients with single or bilateral maxillary lateral incisor agenesis. In $12.6 \%$ of patients PDC coexisted with maxillary lateral incisor agenesis. However, there was no greater risk of occurrence of palatally impacted canines in patients with bilateral hypodontia of the lateral incisors compared to the unilateral form. According to the researchers, the high percentage of coexistence of both disorders may confirm the guidance theory, according to which the distal part of the root of the maxillary lateral incisor leads the canine bud in the right direction during its long eruption path. The study is in line with the results obtained by Becker et al. [30], who also found a positive correlation between PDC and MLIA (5.5\% of 88 patients with PDC showed agenesis of the maxillary lateral incisors). Celikoglu et al. [20], investigating the co-occurrence of dental anomalies with hypodontia of the maxillary lateral incisors, observed that in a group of 94 patients with MLIA, 66\% of patients suffer from structural defects, size, number or tooth position disorders. Ectopic canine eruption occurred in $21.3 \%$ of patients with MLIA. There were 5.3\% of patients with canine impaction, but the result was not statistically significant. Transmigration of the maxillary canines occurred only in $1.1 \%$ of patients.

Citak et al. [16] stated that the frequency of MLIA coexistence with the presence of dens invaginatus and evaginatus is respectively 1.1 and $2.2 \%$. This result was not statistically significant and did not differ from the general population. Also, the incidence of pulp stones was not greater in patients with maxillary lateral incisor agenesis. However, there was a statistically significant increased frequency of taurodontic teeth in patients with MLIA and it was $42.2 \%$. Dilaceration of the root was also more common (18.9\%) than in the general population (9.5\%). Celikoglu et al. [20] studies have shown that in patients with MLIA, the coexistence of root dilaceration occurs at the level of $6.3 \%$, but this result was not statistically significant for the population of patients with full dentition. The abovementioned coincidence of the shape disorder of the lateral incisor of the opposite side in patients with unilateral form of MLIA, often being at the same time a form of the abnormal shape of this tooth (conical tooth), has been underlined by researchers in several works $[4,16,22,23]$. This anomaly occurred in $15.6 \%$ up to $23.3 \%$ of patients with unilateral agenesis of the maxillary lateral incisor.

Al-Nimri and Bsoul [29] stated that among patients with hypodontia of maxillary lateral incisors, the most common was class I malocclusion (42.3\%), the second was class III malocclusion $(25.2 \%)$, then class II subgroup 2 malocclusion (20.3\%). The most rarely observed was class II subgroup 1 malocclusion (12.2\%). Pinho and Lemons [31] observed that in patients with unilateral and bilateral agenesis of maxillary lateral incisors, the deviation of the upper dental midline is common (in cases of unilateral agenesis, to the affected side) and the distal relationship is most often found on the molars and canines. A study by Celikoglu et al. [20] in which skeletal class was assessed in patients with aplasia of the maxillary lateral incisors showed that in MLIA patients skeletal class I was most common (55.3\%), followed by skeletal class III (28.7\%), and the least frequent skeletal class II (16\%). There was also an increased incidence of skeletal class III in patients with MLIA with reference to the general population. In patients with agenesis, skeletal class III occurred in as many as $28.7 \%$, and in the general population in $11.5 \%[20,32]$. Woodworth et al. [33], comparing cephalograms of patients with hypodontia of the maxillary lateral incisor with the norm, found that in patients with MLIA there occurs reduced length of the maxilla and mandible, reduced anterior cranial base, and shortened nasal bone. There was also a decrease in the vertical relationship, both anterior and posterior face height, and reduction in the mandibular plane angle. Analysis of soft tissues showed that in patients with MLIA the value of the nasolabial angle was on average $10^{\circ}$ lower than the recognized norm. Researchers found that the results obtained gave a general picture very similar to those of cleft patients and this may indicate a weaker development of the craniofacial structures in these patients. Pinho et al. [34] also evaluated the effects of maxillary lateral incisor agenesis on skull structures in their studies. Their results confirmed the results obtained by Woodworth et al. [33]. The length of the maxilla was observed to be reduced (the measurement was made between the ANS-PNS points) and the facial height also was reduced. However, MLIA did not correlate with the change in the inclination of the palatal plane relative to the Frankfurt plane. A study by Bassiouny et al. [35] showed that patients with congenital lack of maxillary lateral incisors have a significant tendency to skeletal class III. The researchers attribute these results to the occurrence of maxillary hypoplasia (retrognathia) in these patients. 


\section{CONCLUSIONS}

Based on information obtained from medical databases and library resources, it can be concluded that hypodontia of the maxillary lateral incisors is a condition predisposing to the co-occurrence of other disorders: size, structure, position and quantity of other permanent teeth. The distal molar and canine relationship was the most common. Studies carried out so far in Europe and worldwide indicate the genetic basis of the problem. Coexistence of the agenesis of permanent teeth, especially the maxillary lateral incisors, was observed in patients with ectopic canine eruption [29, 36]. The frequent lack of maxillary lateral incisors in patients with ectopic eruption, palatally displaced or impacted canines, confirms both guidance and genetic theories, which are cited as potential explanations of this condition [30, 37]. From a clinical point of view, it is extremely important that patients with early-detected maxillary lateral incisor agenesis should be able to check both the radiological and clinical process of maxillary canines' eruption, as it can be stated on the basis of the analysis of the referenced data that they are patients at risk of palatal retention of these teeth. In such cases, it may be necessary to conduct interceptive treatment involving the extraction of the deciduous maxillary canines at the appropriate stage of development [38-40]. Based on the systematic review of the literature it can be concluded that patients with maxillary lateral incisor agenesis also have a decrease in mesiodistal crown dimensions of permanent teeth, especially the anterior teeth, and the crowns of the maxillary central incisors most often have a rectangular shape. For this reason, very often the anterior teeth of patients with MLIA will require an aesthetic shape correction and increase in width. The analysis of the conducted studies also showed that in patients with MLIA, skeletal class III was more frequent than in the general population, shortening the length of the maxilla, and a decrease in the vertical relationship was also noted. Our own study [41] confirmed that the congenital lack of maxillary lateral incisors is one of the symptoms indicating a maxillary deficiency syndrome. So far, no studies showing the frequency of coexistence of the disorders discussed above have been carried out in patients with MLIA in the Polish population.

\section{CONFLICT OF INTEREST}

The authors declare no potential conflicts of interest with respect to the research, authorship, and/or publication of this article.

\section{References}

1. Schalk van der Weide Y, Prahl-Andersen B, Bosman F. Tooth for mation in patients with oligodontia. Angle Orthod 1993; 63: 31-37.
2. Polder BJ, Van't Hof MA, Van der Linden FP, Kuijpers-Jagtman AM. A meta-analysis of the prevalence of dental agenesis of permanent teeth. Community Dent Oral Epid 2004; 32: 217-226.

3. Parkin N, Elcock C, Smith RN, et al. The aetiology of hypodontia: the prevalence, severity and location of hypodontia within families. Arch Oral Biol 2009; 54: S52-S56.

4. Woolf CM. Missing maxillary lateral incisors: a genetic study. Am J Hum Genet 1971; 23: 289.

5. Mostowska A, Biedziak B, Zadurska M, et al. WNT10A coding variants and maxillary lateral incisor agenesis with associated dental anomalies. Eur J Oral Sci 2015; 123: 1-8.

6. De Coster PJ, Marks LA, Martens LC, Huysseune A. Dental agenesis: genetic and clinical perspectives. J Oral Pathol Med 2009; 38: 1-17.

7. Kjær I, Kocsis G, Nodal M, Christensen LR. Aetiological aspects of mandibular tooth agenesis - focusing on the role of nerve, oral mucosa, and supporting tissues. Eur J Orthod 1994; 16: 371-375.

8. Kjær I. Neuro-osteology. Crit Rev Oral Biol Med 1998; 9: 224-244. 9. Daugaard-Jensen J, Nodal M, Skovgaard LT, Kjær I. Comparison of the pattern of agenesis in the primary and permanent dentitions in a population characterized by agenesis in the primary dentition. Int J Paediatr Dent 1997; 7: 143-148.

10. Goodman JR, Jones SP, Hobkirk JA, King PA. Hypodontia: clinical features and the management of mild to moderate hypodontia. Dent Update 1994; 21: 381-384.

11. Larmour CJ, Mossey PA, Thind BS, et al. Hypodontia - a retrospective review of prevalence and etiology. Part I. Quintessence Int 2005; 36: 263-270.

12. Garn SM, Lewis AB: The relationship between third molar agenesis and reduction in tooth number. Angle Orthod 1962; 32: 14-18.

13. Garib DG, Peck S, Gomes SC. Increased occurrence of dental anomalies associated with second-premolar agenesis. Angle Orthod 2009; 79: 436-441.

14. Rakhshan V. Congenitally missing teeth (hypodontia): a review of the literature concerning the etiology, prevalence, risk factors, patterns and treatment. Dent Res J (Isfahan) 2015; 12: 1-13.

15. Nieminen P. Genetic basis of tooth agenesis. J Exp Zool Part B Mol Dev Evol 2009; 312B: 320-342.

16. Citak M, Cakici EB, Benkli YA, et al. Dental anomalies in an orthodontic patient population with maxillary lateral incisor agenesis. Dent Press J Orthod 2016; 21: 98-102.

17. Symons AL, Stritzel F, Stamation J. Anomalies associated with hypodontia of the permanent lateral incisor and second premolar. J Clin Pediatr Dent 1993; 17: 109-111.

18. Baidas L, Hashim H. An anterior tooth size comparison in unilateral and bilateral congenitally absent maxillary lateral incisors. J Contemp Dent Pract 2005; 6: 56-63.

19. Garib DG, Alencar BM, Lauris JR, Baccetti T. Agenesis of maxillary lateral incisors and associated dental anomalies. Am J Orthod Dentofacial Orthop 2010; 137: 732.e1-6.

20. Celikoglu M, Kamak H, Yildirim H, Ceylan I. Investigation of the maxillary lateral incisor agenesis and associated dental anomalies in an orthodontic patient population. Med Oral Patol Oral Cir Bucal 2012; 17: e1068-1073.

21. Pinho T, Tavares P, Maciel P, Pollmann C. Developmental absence of maxillary lateral incisors in the Portuguese population. Eur J Orthod 2005; 27: 443-449.

22. Albashaireh ZS, Khader YS. The prevalence and pattern of hypodontia of the permanent teeth and crown size and shape deformity affecting upper lateral incisors in a sample of Jordanian dental patients. Community Dent Health 2006; 23: 239-243.

23. Stamatiou J, Symons AL. Agenesis of the permanent lateral incisor: distribution, number and sites. J Clin Pediatr Dent 1991; 15: 244-246.

24. Baccetti T. A controlled study of associated dental anomalies. Angle Orthod 1998; 68: 267-274.

25. Yaqoob O, DiBiase AT, Garvey T, Fleming PS. Relationship between bilateral congenital absence of maxillary lateral incisors and anterior tooth width. Am J Orthod Dentofacial Orthop 2011; 139: e229-e233. 
26. Mirabella AD, Kokich VG, Rosa M. Analysis of crown widths in subjects with congenitally missing maxillary lateral incisors. Eur J Orthod 2011; 34: 783-787.

27. Olivadoti A, Doldo T, Treccani M. Morpho-dimensional analysis of the maxillary central incisor clinical crown in cases of congenitally missing upper lateral incisors. Prog Orthod 2009; 10: 12-19.

28. Wright J, Bosio JA, Chou JC, Jiang SS. Maxillary lateral incisor agenesis and its relationship to overall tooth size. J Prosthet Dent 2016; 115: 209-214.

29. Al-Nimri KS, Bsoul E. Maxillary palatal canine impaction displacement in subjects with congenitally missing maxillary lateral incisors. Am J Orthod Dentofacial Orthop 2011; 140: 81-86.

30. Becker A, Smith P, Behar R. The incidence of anomalous maxillary lateral incisors in relation to palatally-displaced cuspids. Angle Orthod 1981; 51: 24-29.

31. Pinho T, Lemos C. Dental repercussions of maxillary lateral incisor agenesis. Eur J Orthod 2011; 34: 698-703.

32. Sayin M, Türkkahraman H. Malocclusion and crowding in an orthodontically referred Turkish population. Angle Orthod 2004; 74: 635-639.

33. Woodworth DA, Sinclair PM, Alexander RG. Bilateral congenita absence of maxillary lateral incisors: a craniofacial and dental cast analysis. Am J Orthod 1985; 87: 280-293.

34. Pinho T, Pollmann C, Calheiros-Lobo MJ, et al. Craniofacial repercussions in maxillary lateral incisors agenesis. Int Orthod 2011; 9 : 274-285.

35. Bassiouny DS, Afify AR, Baeshen HA, et al. Prevalence of maxillary lateral incisor agenesis and associated skeletal characteristics in an orthodontic patient population. Acta Odontol Scand 2016; 74: 456-459.

36. Jang E, Lee K, An S, et al. Retrospective study of association between displacement of maxillary canine and tooth agenesis. J Clin Ped Dent 2015; 39: 488-492.

37. Sambataro S, Baccetti T, Franchi L, Antonini F. Early predictive variables for upper canine impaction as derived from posteroanterior cephalograms. Angle Orthod 2005; 75: 28-34.

38. Ericson S, Kurol J. Early treatment of palatally erupting maxillary canines by extraction of the primary canines. Eur J Orthod 1988; 10: 283-295.

39. Naoumova J, Kurol J, Kjellberg H. Extraction of the deciduous canine as an interceptive treatment in children with palatal displaced canines - part I: shall we extract the deciduous canine or not?. Eur J Orthod 2015; 37: 209-218.

40. Naoumova J, Kürol J, Kjellberg H. Extraction of the deciduous canine as an interceptive treatment in children with palatally displaced canines - part II: possible predictors of success and cut-off points for a spontaneous eruption. Eur J Orthod 2015; 37: 219-229.

41. Williams S, Loster JE, Loster BW. The relationship between maxillary dental and occlusal anomalies: Evidence of a "Maxillary Deficiency Syndrome”. Aust Orthod J 2018; 34: 212-224. 